\title{
Continuous glucose monitoring in patients with type 2 diabetes on hemodialysis
}

\author{
Maurizio Gallieni ${ }^{1,2}$ (1) $\cdot$ Cristina De Salvo ${ }^{2}$ Maria Elena Lunati ${ }^{3} \cdot$ Antonio Rossi $^{3} \cdot$ Francesca D'Addio $^{4} \cdot$ Ida Pastore $^{3}$. \\ Gianmarco Sabiu $^{2} \cdot$ Roberta Miglio $^{2}$ - Gian Vincenzo Zuccotti ${ }^{5} \cdot$ Paolo Fiorina ${ }^{3,4,6}$ (I)
}

Received: 28 December 2020 / Accepted: 27 February 2021 / Published online: 20 March 2021

(c) The Author(s) 2021

\begin{abstract}
Diabetic kidney disease is the leading cause of end-stage kidney disease in high-income countries. The strict control of glycemic oscillations is the principal therapeutic target, but this could be hard to achieve in uremic patients due to their unpredictable insulin sensitivity. Currently, the evaluation of the glycemic profile relies on serum markers (glycated hemoglobin $\mathrm{HbAlc}$, glycated albumin, and fructosamine), capillary glucose blood control (self-monitoring of blood glucose), and interstitial glucose control (continue glucose monitoring). We conducted a systematic review of published articles on continue glucose monitoring in hemodialysis patients with type 2 diabetes, which included 12 major articles.Four studies found significant fluctuations in glucose levels during hemodialysis sessions. All studies reported a higher mean amplitude of glucose variations on the hemodialysis day. Three studies agreed that continue glucose monitoring is better than glycated hemoglobin in detecting these abnormalities. Moreover, continue glucose monitoring was more accurate and perceived as easier to use by patients and their caregivers. In patients with type 2 diabetes on hemodialysis, glucose levels show different variation patterns than the patients on hemodialysis without diabetes. Considering manageability, accuracy, and costeffectiveness, continue glucose monitoring could be the ideal diagnostic tool for the patient with diabetes on hemodialysis.
\end{abstract}

Keywords Diabetes mellitus · Continuous glucose monitoring $\cdot$ Hemodialysis $\cdot$ Chronic kidney disease

\section{Introduction}

Managed by Massimo Federici .

Maurizio Gallieni

maurizio.gallieni@unimi.it

1 Department of Biomedical and Clinical Sciences "Luigi Sacco", Università Di Milano, Milano, Italy

2 Nephrology and Dialysis Unit, ASST Fatebenefratelli Sacco, Milano, Italy

3 Division of Endocrinology, ASST Fatebenefratelli-Sacco, Milan, Italy

4 International Center for T1D, Pediatric Clinical Research Center Romeo Ed Enrica Invernizzi, Department of Biomedical and Clinical Sciences "L. Sacco", Università Di Milano, Milan, Italy

5 Pediatric Clinical Research Center Romeo Ed Enrica Invernizzi, Department of Biomedical and Clinical Sciences "L. Sacco", Università Di Milano and Pediatric Department, Buzzi Children's Hospital, Milan, Italy

6 Nephrology Division, Boston Children's Hospital, Harvard Medical School, Boston, MA, USA
The long-term metabolic complications of type 2 diabetes (T2D), a rising epidemic [1], include macrovascular and microvascular disorders [2-7], which subsequently induce damage to multiple systems and organs, such as cardiovascular dysfunction and renal impairment [8]. Macrovascular complications include stroke, cardiovascular, and peripheral artery disease. Microvascular diseases comprehend neuropathy, retinopathy, and diabetic kidney disease (DKD) [9]. DKD affects approximately $25 \%$ of patients with T2D and is considered the principal cause of end-stage kidney disease in high-income countries [10]. Genetic variability, lifestyle, and diet impact the occurrence of DKD. Notably, the health system organization in the individual country is also a relevant factor [11]. Achievement and maintenance of optimal glycemic control is the principal therapeutic strategy to delay DKD progression as both hypo- and hyperglycemia may exert a negative effect [12]. Intensive treatment regimens can bring to hypoglycemic episodes, which can be hazardous for specific groups of patients, such as those 
affected by DKD [13]. Patients with diabetes and end-stage kidney disease are at high risk of developing coronary, cerebrovascular, and peripheral vascular disease. These complications are the leading causes of death among end-stage kidney disease patients [5, 14]. Also, numerous abnormalities in the hemostatic system as well as in insulin sensitivity have been described in diabetic patients with end-stage renal disease that may play a critical role in increasing the rate of death in this patient's population [15-19]. Glycemic control has emerged to be crucial in this population to improve clinical outcomes and significantly reduce cardiovascular risk and mortality. However, proper blood glucose control is challenging in end-stage kidney disease because of the abnormal tissue sensitivity to insulin [20, 21]. Furthermore, there is a lack of precision by classical markers of glycemic control (i.e., HbA1c and fructosamine) due to analytical interferences, to shortened half-life of red blood cells and to abnormal albumin level [22]. Several techniques are used in patients on hemodialysis for glucose measurement at home and during dialysis; indeed, self-monitoring of blood glucose is still the most used 1 and the traditional method to routinely monitor blood glucose [23]. Unfortunately, selfmonitoring of blood glucose does not provide continuous measurements, thus making the evaluation of the patient's glycemic profile incomplete, resulting in glycemic fluctuations. Since 1999, continuous glucose monitoring (CGM) is increasingly being used because it allows real-time blood glucose evaluation. The device records up to 280 measurements per day (generally every $1-5 \mathrm{~min}$ ) and has a transmitter that stores or sends the values (generally every 5-15 min) to a receiver. The glucose sensor reading calibration requires capillary blood sugar measurement with a traditional glucose meter (two/four tests per day) [24]. The glucose concentration in the interstitial fluid generally closely approximates that of blood glucose, particularly when glucose concentrations are stable [25], while during periods of rapid glucose change, the lag can be greater. The mean absolute relative difference (MARD) has become popular for evaluating the overall accuracy of the CGM [26]. There are two types of CGM: (i) RT-CGM allows real-time measurement of blood glucose, and (ii) r-CGM (retrospective CGM) allows to record a series of measures but real-time data results are not available directly to patients, and the physician will have access to them at the end of the monitoring period. In 2014, a new category of device was introduced, the flash glucose monitoring system (FGM) that allows the obtainment of glucose values instantly by scanning the glucose sensor with the reader, producing real-time on-demand glucose data. The aim of this review was to analyze the available literature on the use of continuous glucose monitoring in patients with type 2 diabetes on hemodialysis and demonstrate whether CGM may represent a reliable tool to reduce glucose variability and improve diabetes management in that fragile patient's population.

\section{Methods}

\section{Sources}

We used MEDLINE (1976-present) and Cochrane Library as the primary sources of literature search. We considered only human subjects and the English language. We undertook a literature review searching for multiple pairs of keywords, including "continuous glucose monitoring and hemodialysis," "continuous glucose monitoring and end-stage renal disease," and "continuous glucose monitoring and dialysis." We considered any study, including case reports, observational studies, and RCT. Our research with key relevant search words produced 552 results. We excluded duplicates. We excluded studies on pediatric patients. The majority of the studies reviewed included patients with type 2 diabetes. There were only a few articles which had a population of patient with type 1 diabetes and secondary diabetes. With regard to kidney replacement therapy, hemodialysis, and peritoneal dialysis, only three studies analyzed a population of peritoneal dialysis patients, and one of them was a case report [27]; therefore and because of different daily glucose profile, peritoneal dialysis studies were not included in the analysis. Moreover, one article utilized CGM to compare the efficacy of two oral glucose-lowering drugs [28]. After reviewing all studies' titles and abstracts, we selected 12 of them as appropriate for full-text reading and further analysis [24, 29-39]. Table 1 shows baseline patient's characteristics, while studies design, the outcome of interest, and findings are reported in Table 2. The main outcome in 10 out of the 12 studies analyzed was to monitor the glycemic profile and assess blood glucose variability in hemodialysis patients. In one study the main endpoint was to evaluate the effectiveness of glycated albumin in monitoring the glycometabolic control as compared to glycated hemoglobin in hemodialysis patients [30]. In one study the main endpoint was to assess whether glycemic monitoring may guide therapeutic decision on insulin treatment in hemodialysis patients [36].

\section{Results}

\section{CGM and hypoglycemic risk in hemodialysis}

The augmented risk of TBR (time below range) during dialysis days and a greater reliability of CGM, compared to glycated hemoglobin, has been hypothesized by Kazempour-Ardebili et al. [34]. The study showed average 24-h glucose values significantly higher during non-dialysis 
Table 1 Baseline patients' characteristics of the selected studies $(n=12)$

\begin{tabular}{|c|c|c|c|c|c|c|c|c|}
\hline \multirow[t]{3}{*}{ References } & & \multicolumn{7}{|c|}{ Patient's characteristics } \\
\hline & & \multirow[t]{2}{*}{ No. of patients } & \multirow[t]{2}{*}{ Age (years) } & \multicolumn{2}{|l|}{ Sex } & \multirow[t]{2}{*}{ Types of diabetes } & \multirow{2}{*}{$\begin{array}{l}\text { Diabetes duration } \\
\text { (months) }\end{array}$} & \multirow{2}{*}{$\begin{array}{l}\text { Dialysis duration } \\
\text { (months) }\end{array}$} \\
\hline & & & & Male & Female & & & \\
\hline Gai et al. [24] & & 12 & $62 \pm 14$ & $9(75 \%)$ & $3(25 \%)$ & II & $39.6(1.9-125.4)$ & $21.2(2.2-41.7)$ \\
\hline \multirow[t]{2}{*}{ Jin et al. [31] } & ESDKD & 36 & $62 \pm 13$ & $29(79 \%)$ & $7(21 \%)$ & II & $156 \pm 84$ & l \\
\hline & ESKD & 10 & $65 \pm 13$ & $8(80 \%)$ & $2(20 \%)$ & l & $0 \pm 0$ & l \\
\hline \multicolumn{2}{|l|}{ Jung et al. [33] } & 9 & $67 \pm 9$ & l & l & II & $288 \pm 108$ & l \\
\hline \multicolumn{2}{|c|}{ Képénékian et al. [29] } & 27 & $66 \pm 9$ & $9(32 \%)$ & $19(68 \%)$ & II & $273 \pm 117$ & $43 \pm 30$ \\
\hline \multicolumn{2}{|c|}{ Chantrel et al. [29] } & 33 & $66 \pm 8$ & $19(58 \%)$ & $14(42 \%)$ & II & $276 \pm 132$ & $46 \pm 31$ \\
\hline \multicolumn{2}{|l|}{ Mirani et al. [36] } & 12 & $62 \pm 10$ & $7(58 \%)$ & $5(42 \%)$ & II & $180 \pm 96$ & $27.6 \pm 15.6$ \\
\hline \multirow[t]{2}{*}{ Riveline et al. [38] } & ESDKD & 19 & $64 \pm 10$ & $8(42 \%)$ & $11(58 \%)$ & II & $252 \pm 132$ & $24(13-35)$ \\
\hline & Non-HD & 39 & $65 \pm 6$ & $25(64 \%)$ & $14(36 \%)$ & l & $204 \pm 84$ & l \\
\hline \multicolumn{2}{|c|}{$\begin{array}{l}\text { Kazempour-Ardebili et al. } \\
\text { [34] }\end{array}$} & 17 & $61 \pm 9$ & $13(76 \%)$ & $4(23 \%)$ & II & $225 \pm 91$ & $48 \pm 31.2$ \\
\hline \multicolumn{2}{|l|}{ Divani et al. [30] } & 37 & $62 \pm 17$ & $20(54 \%)$ & $17(46 \%)$ & l & l & $37.0 \pm 16.9$ \\
\hline \multicolumn{2}{|l|}{ Mori et al. [37] } & 1 & 68 & $1(100 \%)$ & $0(0 \%)$ & l & 492 & 216 \\
\hline \multicolumn{2}{|l|}{ Joubert et al. [32] } & 15 & $61 \pm 15$ & $8(53 \%)$ & $7(47 \%)$ & I and II & $230 \pm 91.2$ & $78 \pm 83$ \\
\hline \multicolumn{2}{|l|}{ Yajima T et al. [39] } & 13 & $63.5 \pm 11.3$ & $11(85 \%)$ & $2(15 \%)$ & II & 1 & $7.3(4.3-28.4)$ \\
\hline
\end{tabular}

$E S D K D$ end-stage diabetic kidney disease, $E S K D$ end-stage kidney disease

days than dialysis days independent of energy intake, with a higher risk of TBR within $24 \mathrm{~h}$ of dialysis. The difference between average 24-h glucose levels for the dialysis-free day to the dialysis day ranged from -2.1 to $10.4 \mathrm{mmol} / \mathrm{l}(-38$ to $187 \mathrm{mg} / \mathrm{dl}$ ). Similar conclusions were obtained by Gai et al. [24]. They analyzed the utility of CGM as an extended glycemic control method in 12 patients with T2D on hemodialysis. During dialysis, serum glucose diminished, while TAR (time above range) episodes were more frequent in the post-dialysis period. CGM was an excellent method to detect these fluctuations. The association of hemodialysis treatment and TBR risk was evaluated also by Jung et al. [33]. In 9 patients with T2D on hemodialysis using CGM, daily glucose fluctuations were not associated, while hypoglycemia was, with hemodialysis. Also, Riveline et al. [38] evaluated the clinical performance of CGM in patients with T2D on hemodialysis. The study compared 19 patients with T2D on hemodialysis with 39 patients with T2D not on hemodialysis. The comparison between hemodialysis day and non-hemodialysis days differed remarkably in the first $3 \mathrm{~h}$ of dialysis. During this time, the mean glucose concentration was significantly lower than in non-hemodialysis days, although only two patients had intra-dialytic hypoglycemia ( $<70 \mathrm{mg} / \mathrm{dl}$ ). Recently, a case report by Mori et al. [37] described a patient with T2D on hemodialysis monitored with CGM, in which several TBR episodes were recorded during hemodialysis session. To summarize, there is a general agreement that CGM reduces TBR episodes in patients with T2D on hemodialysis.

\section{CGM and glucose variability in hemodialysis}

Blood glucose variability in patients with T2D on hemodialysis was quite extensively investigated. Mirani et al. [36] studied 12 patients with T2D on hemodialysis for two days, including one hemodialysis day and the following non-hemodialysis day. The mean 24-h glycemic value and the mean amplitude of glycemic excursions (MAGE) were significantly higher in the hemodialysis day than the nonhemodialysis day. The study also showed a direct correlation between the mean glucose concentration and glycated hemoglobin, whereas no association existed between the glucose profile variability and glycated hemoglobin. Jin et al. [31] aimed to characterize the blood glucose fluctuations during hemodialysis with CGM. Glycemic variability was assessed by measuring the MAGE. Forty-six patients were divided into 2 groups: 36 patients with T2D on hemodialysis and 10 patients without T2D on hemodialysis. They found out that the first group had larger and more significant glycemic fluctuations. Moreover, glycated hemoglobin was inaccurate since it did not reflect the correct blood glucose variability during an extended period. Similar conclusions have been reported by Chantrel et al. [29]. They analyzed 33 patients with T2D on hemodialysis in insulin treatment with 3 CGM sessions of $48 \mathrm{~h}$ each, including a dialysis session, over 3 months. CGM results were analyzed during and after hemodialysis and in other different day periods according to meals. Mean glucose values, MAGE, and coefficient of variation (\%) improved, whereas the frequency of TBR was higher during hemodialysis sessions. Moreover, significant 
Table 2 Outcomes of interests and findings of the selected studies $(n=12)$

\begin{tabular}{|c|c|c|c|c|c|c|c|}
\hline References & No. of pts & Design & Arms & Type of CGM & $\begin{array}{l}\text { Follow- } \\
\text { up } \\
\text { (Days) }\end{array}$ & Outcome of interest & Findings \\
\hline Gai et al. [24] & 36 & $\begin{array}{l}\text { Perspective observa- } \\
\text { tional }\end{array}$ & 1 & r-CGM & 6 & $\begin{array}{l}\text { Glycemic monitoring } \\
\text { in HD }\end{array}$ & $\begin{array}{l}\text { Glycemic fluctuations } \\
\text { and hypoglycemia } \\
\text { during HD }\end{array}$ \\
\hline Jin et al. [31] & 46 & $\begin{array}{l}\text { Perspective observa- } \\
\text { tional }\end{array}$ & 2 & r-CGM & 3 & $\begin{array}{l}\text { Glycemic monitoring } \\
\text { in HD }\end{array}$ & $\begin{array}{l}\text { Glycemic fluctuations } \\
\text { during HD }\end{array}$ \\
\hline Jung et al. [33] & 9 & $\begin{array}{l}\text { Perspective observa- } \\
\text { tional }\end{array}$ & 1 & r-CGM & 6 & $\begin{array}{l}\text { Glycemic monitoring } \\
\text { in HD }\end{array}$ & $\begin{array}{l}\text { No glycemic fluctua- } \\
\text { tions but increased } \\
\text { risk of hypoglycemia } \\
\text { during HD }\end{array}$ \\
\hline Chantrel et al. [29] & 33 & $\begin{array}{l}\text { Perspective observa- } \\
\text { tional }\end{array}$ & 1 & rt-CGM & 90 & $\begin{array}{l}\text { Glycemic monitoring } \\
\text { in } \mathrm{HD}\end{array}$ & $\begin{array}{l}\text { Glycemic fluctuations } \\
\text { and hypoglycemia } \\
\text { during HD }\end{array}$ \\
\hline Mirani et al. [36] & 12 & $\begin{array}{l}\text { Perspective observa- } \\
\text { tional }\end{array}$ & 1 & r-CGM & 2 & $\begin{array}{l}\text { Glycemic monitoring } \\
\text { in } \mathrm{HD}\end{array}$ & $\begin{array}{l}\text { Large glycemic fluc- } \\
\text { tuations during HD }\end{array}$ \\
\hline Riveline et al. [38] & 58 & $\begin{array}{l}\text { Perspective observa- } \\
\text { tional }\end{array}$ & 2 & r-CGM & 4 & $\begin{array}{l}\text { Glycemic monitoring } \\
\text { in HD }\end{array}$ & $\begin{array}{l}\text { No glycemic fluctua- } \\
\text { tions during HD }\end{array}$ \\
\hline $\begin{array}{l}\text { Kazempour-Ardebili } \\
\text { et al. [34] }\end{array}$ & 17 & $\begin{array}{l}\text { Perspective observa- } \\
\text { tional }\end{array}$ & 1 & r-CGM & 2 & $\begin{array}{l}\text { Glycemic monitoring } \\
\text { in HD }\end{array}$ & $\begin{array}{l}\text { Glycemic fluctuations } \\
\text { and hypoglycemia } \\
\text { during HD }\end{array}$ \\
\hline Divani et al. [30] & 37 & $\begin{array}{l}\text { Perspective observa- } \\
\text { tional }\end{array}$ & 1 & r-CGM & 7 & $\begin{array}{l}\text { Validity/accuracy of } \\
\text { CGM in HD }\end{array}$ & $\begin{array}{l}\text { CGM is accurate in } \\
\text { glycemic monitoring }\end{array}$ \\
\hline Képénékian et al. [29] & 27 & $\begin{array}{l}\text { Perspective observa- } \\
\text { tional }\end{array}$ & 1 & rt-CGM & 90 & $\begin{array}{l}\text { Improving DM therapy } \\
\text { in HD }\end{array}$ & $\begin{array}{l}\text { Improved glycemic } \\
\text { control with CGM }\end{array}$ \\
\hline Joubert et al. [32] & 15 & $\begin{array}{l}\text { Perspective observa- } \\
\text { tional }\end{array}$ & 1 & r-CGM & 90 & $\begin{array}{l}\text { Improving DM therapy } \\
\text { in HD }\end{array}$ & $\begin{array}{l}\text { Large glycemic } \\
\text { fluctuations during } \\
\text { HD and improved } \\
\text { glycemic control } \\
\text { with CGM }\end{array}$ \\
\hline Mori et al. [37] & 1 & Case report & I & rt-CGM & 2 & $\begin{array}{l}\text { Glycemic monitoring } \\
\text { in } \mathrm{HD}\end{array}$ & $\begin{array}{l}\text { Glycemic fluctuations } \\
\text { and hypoglycemia } \\
\text { during HD }\end{array}$ \\
\hline Yajima T et al. [39] & 13 & $\begin{array}{l}\text { Perspective observa- } \\
\text { tional }\end{array}$ & 1 & r-CGM/ FGM & 2 & $\begin{array}{l}\text { Glycemic monitoring } \\
\text { in HD }\end{array}$ & $\begin{array}{l}\text { Accuracy of FGM } \\
\text { in HD }\end{array}$ \\
\hline
\end{tabular}

PTS patients, $H D$ hemodialysis, $C G M$ continuous glucose monitoring, ESDKD end-stage diabetic kidney disease, ESKD end-stage kidney disease

differences were observed in glucose levels before and $2 \mathrm{~h}$ after breakfast. Patients with T2D on hemodialysis are subject to the high variability of glucose profiles, and standard laboratory assays would miss such variations. Also, the use of hypoglycemic drug may enhance glucose variability and increase the risk for hospitalization in these patients [40]. In conclusion, CGM would be a handy tool to detect such variations and manage these complex patients properly.

\section{CGM and improvement of diabetes management in hemodialysis}

The role of CGM as a tool to manage the insulin regimen in patients with T2D on hemodialysis was tested by Képénékian et al. [35]. CGM was applied for $54 \mathrm{~h}$ at baseline and a 3-month follow-up in 28 patients to adapt insulin therapy to the CGM values. After 3 months, patients demonstrated a significant reduction of glycated hemoglobin and CGM glucose values, with no episodes of severe hypoglycemia. Furthermore, patients experienced less episodes of TAR with reduction in insulin requirements. The study did not focus on analyzing glycemic profiles on hemodialysis days compared with non-hemodialysis days, even though it underscored the absence of intra-dialytic TBR episodes. Képénékian et al. concluded that the CGM-adapted insulin regimen could be a useful tool for managing diabetes in patients on hemodialysis. Also, the DIALYDIAB pilot study [32] aimed to analyze the use of CGM to detect glucose fluctuations in patients with diabetes on hemodialysis. Fifteen patients were enrolled and were studied for the first period by self-monitoring blood glucose 3 times a day and then for the second 
period by CGM. They observed that during CGM monitoring, treatment changes took place more frequently, resulting in better blood glucose control and fewer TBR episodes. Finally, Divani et al. [30] compared various monitoring blood glucose methods over 7 days in hemodialysis patients using CGM. The study concluded that 7-day-long CGM is better to assess poor glycometabolic control as compared to glycated hemoglobin. This study also underscored the accuracy of CGM. Regarding the accuracy of FGM in hemodialysis patients, Yajima et al. [39] studied 13 uremic patients undergoing simultaneously FGM, CGM and self-monitoring blood glucose during hemodialysis and non-hemodialysis days. Their conclusions showed that the use of FGM may be clinically relevant in this population, but MARDs for TBR and TIR were significantly higher than MARD for TAR. Moreover, MARD for FGM was significantly higher than for CGM, in both hemodialysis and non-hemodialysis day, while MARD for CGM on hemodialysis day was significantly higher than that on non-hemodialysis day, due to the higher glycemic excursion as reported by Jin et al. [31]. More detailed studies are needed to evaluate comparison between FGM or CGM during and after hemodialysis.

\section{Conclusions}

The review of the literature surrounding the use of CGM in hemodialysis revealed few important messages. First and foremost, the mean amplitude of glucose variations was higher in the hemodialysis days than in those without hemodialysis. The glucose concentration in the dialysis fluid, hemodialysis sessions duration, hemofiltration of drugs, and the time frame between meals and hemodialysis sessions are probably the factors responsible for the observed differences. Second, the use of CGM may reduce hypoglycemic episodes which appeared increased during hemodialysis. The conclusion is that CGM would be a useful tool in detecting these abnormalities and in improving the management of diabetes [32]. All the studies identified CGM as an appropriate and reliable tool to detect glycemic variations and hypoglycemic episodes in this population, particularly on the hemodialysis day. Furthermore, several studies have shown that CGM is much better perceived by patients and their caregivers, who appreciated the possibility of easily accessing blood glucose data [41]. The device provides trend arrows that add context to each glucose reading; this has a critical impact on insulin dosing decision and hypoglycemia prevention. Only 1 study assessed CGM's cost-effectiveness, but it considered only patients with type 1 diabetes and anyway CGM was costeffective [42]. In patients without chronic kidney disease (CKD), the accuracy of the CGM may vary depending on the blood glucose concentration and the rate of blood glucose change $[43,44]$. A comparison of the accuracy of FGM and
CGM in non-CKD patients recently demonstrated that both systems perform safely and efficiently but accuracy of the CGM sensor appear higher across all glucose values except in hypoglycemia [45]. This review has several limitations, including the limited number of patients and the short-term follow-up. Despite the prospective nature, most of the studies remained observational studies and almost all of them without a comparison arm. Besides, not all studies focused on the same parameters, some observed glycemic variations, while others focused on the modulation of diabetes treatment based on the CGM device results. In conclusion, the use of CGM in patients with diabetes on hemodialysis ensures the improvement in glucose control and reduces the risk of hypoglycemia, especially in adults with type 1 diabetes, still experiencing suboptimal glycemic control. CGM could improve patients' management and quality of life and it is cost-effective.

Funding Open access funding provided by Università degli Studi di Milano within the CRUI-CARE Agreement. The research was not financially supported.

Code availability Not applicable.

Declaration

Conflict of interest The authors declare no conflicts.

Availability of data and material Not applicable.

Ethical approval Not applicable.

Consent to participate Not applicable.

Consent for publication Not applicable.

Open Access This article is licensed under a Creative Commons Attribution 4.0 International License, which permits use, sharing, adaptation, distribution and reproduction in any medium or format, as long as you give appropriate credit to the original author(s) and the source, provide a link to the Creative Commons licence, and indicate if changes were made. The images or other third party material in this article are included in the article's Creative Commons licence, unless indicated otherwise in a credit line to the material. If material is not included in the article's Creative Commons licence and your intended use is not permitted by statutory regulation or exceeds the permitted use, you will need to obtain permission directly from the copyright holder. To view a copy of this licence, visit http://creativecommons.org/licenses/by/4.0/.

\section{References}

1. de Ritter R, de Jong M, Vos RC et al (2020) Sex differences in the risk of vascular disease associated with diabetes. Biol Sex Differ $11: 1$ 
2. Astorri E, Fiorina P, Gavaruzzi G, Astorri A, Magnati G (1997) Left ventricular function in insulin-dependent and in non-insulindependent diabetic patients: radionuclide assessment. Cardiology $88: 152-155$

3. Bassi R, Fiorina P (2011) Impact of islet transplantation on diabetes complications and quality of life. Curr Diab Rep 11:355-363

4. D'Addio F, La Rosa S, Maestroni A et al (2015) Circulating IGF-I and IGFBP3 levels control human colonic stem cell function and are disrupted in diabetic enteropathy. Cell Stem Cell 17:486-498

5. Fiorina P, Lattuada G, Ponari O, Silvestrini C, DallAglio P (1996) Impaired nocturnal melatonin excretion and changes of immunological status in ischaemic stroke patients. Lancet 347:692-693

6. Fiorina P, Vergani A, Bassi R et al (2014) Role of podocyte B7-1 in diabetic nephropathy. J Am Soc Nephrol 25:1415-1429

7. Perseghin G, Fiorina P, De Cobelli F et al (2005) Cross-sectional assessment of the effect of kidney and kidney-pancreas transplantation on resting left ventricular energy metabolism in type 1 diabetic-uremic patients: a phosphorous-31 magnetic resonance spectroscopy study. J Am Coll Cardiol 46:1085-1092

8. Deshpande AD, Harris-Hayes M, Schootman M (2008) Epidemiology of diabetes and diabetes-related complications. Phys Ther 88:1254-1264

9. Orasanu G, Plutzky J (2009) The pathologic continuum of diabetic vascular disease. J Am Coll Cardiol 53:S35-42

10. Wang G, Ouyang J, Li S et al (2019) The analysis of risk factors for diabetic nephropathy progression and the construction of a prognostic database for chronic kidney diseases. J Transl Med 17:264

11. Randhawa G (2003) Developing culturally competent renal services in the United Kingdom: tackling inequalities in health. Transplant Proc 35:21-23

12. Shurraw S, Hemmelgarn B, Lin M et al (2011) Association between glycemic control and adverse outcomes in people with diabetes mellitus and chronic kidney disease: a population-based cohort study. Arch Intern Med 171:1920-1927

13. Drechsler C, Krane V, Ritz E, Marz W, Wanner C (2009) Glycemic control and cardiovascular events in diabetic hemodialysis patients. Circulation 120:2421-2428

14. Abbott KC, Bakris GL (2002) Treatment of the diabetic patient: focus on cardiovascular and renal risk reduction. Prog Brain Res 139:289-298

15. Fiorina P, Folli F, D’Angelo A et al (2004) Normalization of multiple hemostatic abnormalities in uremic type 1 diabetic patients after kidney-pancreas transplantation. Diabetes 53:2291-2300

16. Folli F, Sinha MK, Brancaccio D, Caro JF (1986) Insulin resistance in uremia: in vitro model in the rat liver using human serum to study mechanisms. Metabolism 35:989-998

17. Pellegatta F, Folli F, Ronchi P, Caspani L, Galli L, Vicari AM (1993) Deranged platelet calcium homeostasis in poorly controlled IDDM patients. Diabetes Care 16:178-183

18. Vicari AM, Monzani ML, Pellegatta F, Ronchi P, Galli L, Folli F (1994) Platelet calcium homeostasis is abnormal in patients with severe arteriosclerosis. Arterioscler Thromb 14:1420-1424

19. Vicari AM, Taglietti MV, Pellegatta F et al (1996) Deranged platelet calcium homeostasis in diabetic patients with end-stage renal failure. a possible link to increased cardiovascular mortality? Diabetes Care 19:1062-6

20. Bailey JL (2013) Insulin resistance and muscle metabolism in chronic kidney disease. ISRN Endocrinol 2013:329606

21. Mak RH, DeFronzo RA (1992) Glucose and insulin metabolism in uremia. Nephron 61:377-382

22. Lee KF, Szeto YT, Benzie IF (2002) Glycohaemoglobin measurement: methodological differences in relation to interference by urea. Acta Diabetol 39:35-39
23. Ogawa T, Murakawa M, Matsuda A et al (2012) Endogenous factors modified by hemodialysis may interfere with the accuracy of blood glucose-measuring device. Hemodial Int 16:266-273

24. Gai M, Merlo I, Dellepiane S et al (2014) Glycemic pattern in diabetic patients on hemodialysis: continuous glucose monitoring (CGM) analysis. Blood Purif 38:68-73

25. Rossetti P, Bondia J, Vehi J, Fanelli CG (2010) Estimating plasma glucose from interstitial glucose: the issue of calibration algorithms in commercial continuous glucose monitoring devices. Sensors (Basel) 10:10936-10952

26. Reiterer F, Polterauer P, Schoemaker M et al (2017) Significance and reliability of MARD for the accuracy of CGM systems. J Diabetes Sci Technol 11:59-67

27. Mori T, Chida M, Oba I et al (2014) Diurnal variations of blood glucose by continuous blood glucose monitoring in peritoneal dialysis patients with diabetes. Adv Perit Dial 30:54-59

28. Yajima T, Yajima K, Hayashi M, Takahashi H, Yasuda K (2016) Efficacy and safety of teneligliptin in addition to insulin therapy in type 2 diabetes mellitus patients on hemodialysis evaluated by continuous glucose monitoring. Diabetes Res Clin Pract 122:78-83

29. Chantrel F, Sissoko H, Kepenekian L et al (2014) Influence of dialysis on the glucose profile in patients with diabetes: usefulness of continuous glucose monitoring. Horm Metab Res 46:810-813

30. Divani M, Georgianos PI, Didangelos T et al (2018) Comparison of glycemic markers in chronic hemodialysis using continuous glucose monitoring. Am J Nephrol 47:21-29

31. Jin YP, Su XF, Yin GP et al (2015) Blood glucose fluctuations in hemodialysis patients with end stage diabetic nephropathy. J Diabetes Complications 29:395-399

32. Joubert M, Fourmy C, Henri P, Ficheux M, Lobbedez T, Reznik Y (2015) Effectiveness of continuous glucose monitoring in dialysis patients with diabetes: the DIALYDIAB pilot study. Diabetes Res Clin Pract 107:348-354

33. Jung HS, Kim HI, Kim MJ et al (2010) Analysis of hemodialysisassociated hypoglycemia in patients with type 2 diabetes using a continuous glucose monitoring system. Diabetes Technol Ther 12:801-807

34. Kazempour-Ardebili S, Lecamwasam VL, Dassanyake T et al (2009) Assessing glycemic control in maintenance hemodialysis patients with type 2 diabetes. Diabetes Care 32:1137-1142

35. Kepenekian L, Smagala A, Meyer L et al (2014) Continuous glucose monitoring in hemodialyzed patients with type 2 diabetes: a multicenter pilot study. Clin Nephrol 82:240-246

36. Mirani M, Berra C, Finazzi S et al (2010) Inter-day glycemic variability assessed by continuous glucose monitoring in insulintreated type 2 diabetes patients on hemodialysis. Diabetes Technol Ther 12:749-753

37. Mori K, Emoto M, Abe M, Inaba M (2019) Visualization of blood glucose fluctuations using continuous glucose monitoring in patients undergoing hemodialysis. J Diabetes Sci Technol 13:413-414

38. Riveline JP, Teynie J, Belmouaz S et al (2009) Glycaemic control in type 2 diabetic patients on chronic haemodialysis: use of a continuous glucose monitoring system. Nephrol Dial Transplant 24:2866-2871

39. Yajima T, Takahashi H, Yasuda K (2020) Comparison of Interstitial Fluid Glucose Levels Obtained by Continuous Glucose Monitoring and Flash Glucose Monitoring in Patients With Type 2 Diabetes Mellitus Undergoing Hemodialysis. J Diabetes Sci Technol 14:1088-1094

40. Berra C, De Fazio F, Azzolini E et al (2019) Hypoglycemia and hyperglycemia are risk factors for falls in the hospital population. Acta Diabetol 56:931-938

41. Hommel E, Olsen B, Battelino T et al (2014) Impact of continuous glucose monitoring on quality of life, treatment satisfaction, and 
use of medical care resources: analyses from the SWITCH study. Acta Diabetol 51:845-851

42. Wan W, Skandari MR, Minc A et al (2018) Cost-effectiveness of Continuous Glucose Monitoring for Adults With Type 1 Diabetes Compared With Self-Monitoring of Blood Glucose: The DIAMOND Randomized Trial. Diabetes Care 41:1227-1234

43. Pleus S, Schoemaker M, Morgenstern K et al (2015) Rate-ofChange Dependence of the Performance of Two CGM Systems During Induced Glucose Swings. J Diabetes Sci Technol 9:801-807

44. Rodbard D (2014) Characterizing accuracy and precision of glucose sensors and meters. J Diabetes Sci Technol 8:980-985
45. Boscari F, Galasso S, Acciaroli G et al (2018) Head-to-head comparison of the accuracy of Abbott FreeStyle Libre and Dexcom G5 mobile. Nutr Metab Cardiovasc Dis 28:425-427

Publisher's Note Springer Nature remains neutral with regard to jurisdictional claims in published maps and institutional affiliations. 